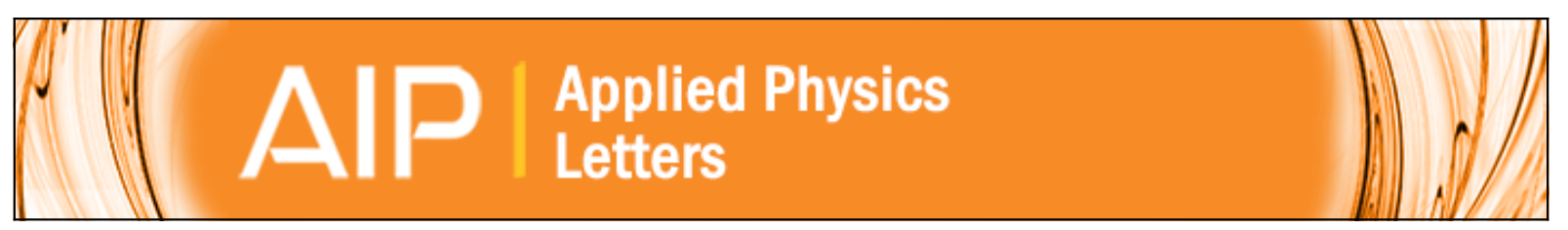

\title{
Magnetoelectric properties of flexible BiFeO3/Ni tapes
}

L. Yan, M. Zhuo, Z. Wang, J. Yao, N. Haberkorn, S. Zhang, L. Civale, J. Li, D. Viehland, and Q. X. Jia

Citation: Applied Physics Letters 101, 012908 (2012); doi: 10.1063/1.4731780

View online: $\mathrm{http} / / / \mathrm{dx}$.doi.org/10.1063/1.4731780

View Table of Contents: http://scitation.aip.org/content/aip/journal/apl/101/1?ver=pdfcov

Published by the AIP Publishing

A AlP Re-register for Table of Content Alerts 


\title{
Magnetoelectric properties of flexible $\mathrm{BiFeO}_{3} / \mathrm{Ni}$ tapes
}

\author{
L. Yan, ${ }^{1, \text { a) }}$ M. Zhuo, ${ }^{1}$ Z. Wang, ${ }^{2}$ J. Yao, ${ }^{2}$ N. Haberkorn, ${ }^{3}$ S. Zhang, ${ }^{1}$ L. Civale, ${ }^{3}$ J. Li, ${ }^{2}$ \\ D. Viehland, ${ }^{2}$ and Q. X. Jia ${ }^{1, a)}$ \\ ${ }^{1}$ Center for Integrated Nanotechnologies, Los Alamos National Laboratory, Los Alamos, \\ New Mexico 87545, USA \\ ${ }^{2}$ Department of Materials Science and Engineering, Virginia Tech, Blacksburg, Virginia 24061, USA \\ ${ }^{3}$ Superconductivity Technology Center, Los Alamos National Laboratory, Los Alamos, \\ New Mexico 87545, USA
}

(Received 26 March 2012; accepted 11 June 2012; published online 5 July 2012)

\begin{abstract}
We report ferroelectric (FE), ferromagnetic, and magnetoelectric (ME) properties of $\mathrm{BiFeO}_{3}$ films directly deposited on flexible magnetic Ni tapes. Without use of metal-oxide and/or noble metal buffer layer between the $\mathrm{BiFeO}_{3}$ and the $\mathrm{Ni}$, both ferroelectric and magnetic properties of the film and the substrate are preserved. X-ray diffraction and transmission electron microscopy analyses confirm the formation of preferentially oriented (110) $\mathrm{BiFeO}_{3}$ film on Ni tapes. The $\mathrm{BiFeO}_{3}$ film has a saturation polarization and a piezoelectric $d_{33}$ coefficient of $69 \mu \mathrm{C} / \mathrm{cm}^{2}$ and $52 \mathrm{pm} / \mathrm{V}$, respectively. The $\mathrm{BiFeO}_{3} / \mathrm{Ni}$ tape shows a magnetoelectric coefficient of $3.5 \mathrm{mV} / \mathrm{cm}$. Oe. (c) 2012 American Institute of Physics. [http://dx.doi.org/10.1063/1.4731780]
\end{abstract}

Tremendous efforts have been devoted to integrate ferroelectric films with metal substrates since such an integration will lead to devices such as multilayer capacitors, piezoelectric sensors, ultrasonic actuators, energy harvesters, magnetoelectric (ME) sensor, etc. ${ }^{1-5}$ Ferroelectric films directly deposited on metal substrate have their great advantages compared with films on ceramics. For example, base metal substrates (nickel, copper, and iron) cost far less than single crystal ceramic substrates. The use of metal as substrates can greatly reduce the cost of the assembly. ${ }^{2}$ Metal tapes are flexible compared with commonly used ceramic crystal substrates. Such feature enables the devices (piezoelectric actuator, energy harvester, etc.) to operate under extreme conditions of high strain and vibration environments. Flexible organic ferroelectric films have been demonstrated $^{6}$ and may find applications in specific cases. On the other hand, an integration of oxide-based ferroelectric films with flexible metal substrates offers other opportunities for applications since oxide-based ferroelectric materials exhibit much improved ferroelectric and dielectric properties at high temperature. Similar to the superconducting tapes, ${ }^{7}$ the growth of ferroelectric films with desired properties on flexible metal tapes makes it possible to produce large area ferroelectric materials. In addition, one would expect to obtain coupled functionality if one can integrate high performance ferroelectric films with flexible magnetic metal tapes. For example, ME film sensors using ferromagnetic metal tapes as substrates are expect to have much better ME performance because ferroelectric films are not constrained by the thin and flexible substrates. ${ }^{5}$

To deposit ferroelectric films on metal substrates with desired physical properties, multilayer metal-oxides or noble metals are usually used as buffer layers. For example, $\mathrm{LaMnO}_{3} / \mathrm{MgO} / \mathrm{IBAD}-\mathrm{MgO} / \mathrm{Y}_{2} \mathrm{O}_{3} / \mathrm{Al}_{2} \mathrm{O}_{3}$ multi-layers have been used as the buffer between the $\mathrm{BaTiO}_{3}$ film and the

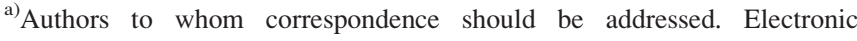
addresses: 1yan@vt.edu and qxjia@lanl.gov.
}

nickel substrate. ${ }^{8}$ Gold has also been used as a buffer between the $\mathrm{BaTiO}_{3}$ and the metglas foil. ${ }^{5}$ It has been a technical challenge in the field to directly deposit ferroelectric films on metal substrates with satisfied polarization and piezoelectricity. The main technical difficulty is that metaloxide thin films are often deposited in an oxygen ambient ( $\sim 100 \mathrm{mTorr})$ at a temperature of $700-900^{\circ} \mathrm{C}$. Under such processing conditions, the base metal is quickly oxidized. In previous reports, ferroelectric $\mathrm{BaTiO}_{3},(\mathrm{Ba}, \mathrm{Sr}) \mathrm{TiO}_{3}$, $\mathrm{Pb}(\mathrm{Zr}, \mathrm{Ti}) \mathrm{O}_{3}$ and $(\mathrm{Pb}, \mathrm{La})(\mathrm{Zr}, \mathrm{Ti}) \mathrm{O}_{3}$ films were directly grown on nickel and copper substrates using pulsed laser deposition (PLD), ${ }^{9-11}$ chemical solution deposition (CSD) ${ }^{2,12-16}$ and sputtering. ${ }^{17,18}$ Most of the reports show the expected structural properties of the films but with limited demonstration of desired dielectric properties. ${ }^{2,13-18}$ In fact, only one report illustrated the ability to deposit $\mathrm{Pb}(\mathrm{Zr}, \mathrm{Ti}) \mathrm{O}_{3}$ film directly on copper foil with satisfied polarization hysteresis loop. ${ }^{2}$ There is no report at all on the ME properties even though these ferroelectric films are directly deposited on magnetic substrates such as $\mathrm{Ni}$ foils.

In the last several years, $\mathrm{BiFeO}_{3}$ has been extensively investigated as one of the most promising ferroelectric materials due to its large polarization $\left(\sim 60 \mu \mathrm{C} / \mathrm{cm}^{2}\right)$ and piezoelectricity $(\sim 75 \mathrm{pm} / \mathrm{V})$ at room temperature. ${ }^{19}$ In this letter, we report the demonstration of ferroelectric $\mathrm{BiFeO}_{3}$ films directly deposited on nickel tapes by pulsed laser deposition. $\mathrm{X}$-ray diffraction (XRD) and transmission electron microscopy (TEM) measurements confirmed the formation of $\mathrm{BiFeO}_{3}$. The $\mathrm{BiFeO}_{3}$ films on $\mathrm{Ni}$ showed ferroelectric and piezoelectric properties comparable to the films on crystal ceramic substrates. Importantly, we report the ME effect of flexible $\mathrm{BiFeO}_{3} / \mathrm{Ni}$ tapes tested by using a traditional $\mathrm{AC}+\mathrm{DC}$ magnetic field method.

$\mathrm{BiFeO}_{3}$ films were directly deposited on $127 \mu$ m thick nickel tapes by pulsed laser deposition. The Ni tapes were polished before the deposition. The thickness of the films was varied between 1 and $1.5 \mu \mathrm{m}$, which was confirmed by TEM. The films were deposited using a $\mathrm{XeCl}$ excimer laser 
with a wavelength of $308 \mathrm{~nm}$ and an energy density of $5 \mathrm{~J} / \mathrm{cm}^{2}$ on the target surface. The substrate temperature and oxygen pressure during deposition were initially optimized for the best structural properties and were then maintained at $540-620^{\circ} \mathrm{C}$ and $30 \mathrm{mT}$ Trr, respectively. The phases of the films were determined using a Philips X'pert high resolution $\mathrm{x}$-ray diffractometer (XRD) equipped with a two bounce hybrid monochromator and an open three-circle Eulerian cradle. The magnetic properties of the Ni tape were measured at $300 \mathrm{~K}$ using a superconducting quantum interference device (SQUID) magnetometer (Quantum Design MPMS magnetometer). Polarization and piezoelectricity of the films were measured by home-made Sawyer-Tower measurement system and piezo-response force microscopy, respectively. The top gold electrodes are deposited by sputtering through a shadow mask with a dimension of $37 \mu \mathrm{m} \times 37 \mu \mathrm{m}$.

$\mathrm{XRD}, \mathrm{TEM}$, and energy-dispersive spectroscopy (EDS) were used to identify the phase and structure of the $\mathrm{BiFeO}_{3}$ films on Ni tapes. As shown in Figure 1(a), the $\mathrm{BiFeO}_{3}$ film is preferentially oriented along (110). Except for the diffractions from $\mathrm{BiFeO}_{3}$ and $\mathrm{Ni}$, no other phases are detected, sug-

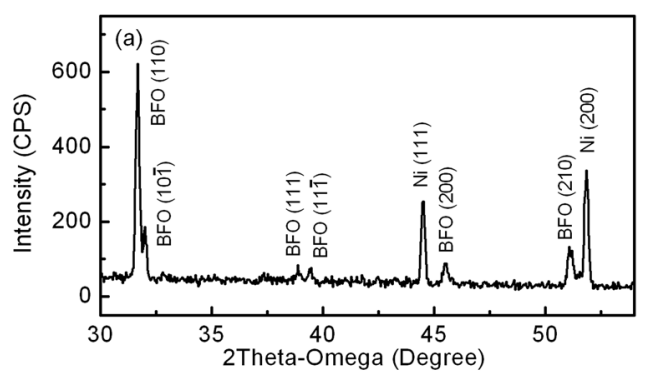

(b)
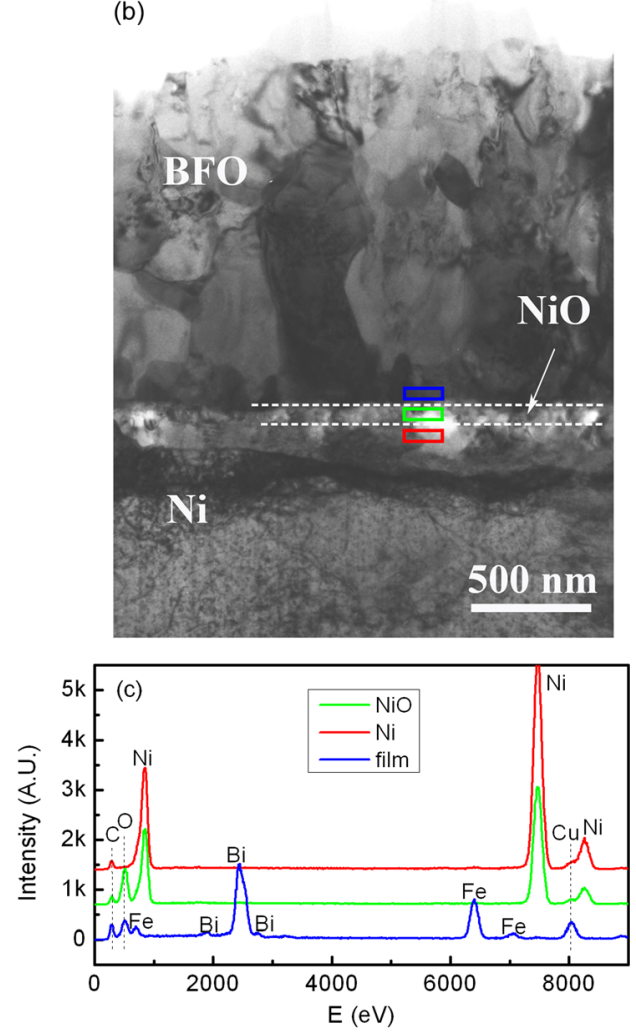

FIG. 1. Structural analysis of the $\mathrm{BiFeO}_{3}$ film directly deposited on the flexible Ni tape (a) XRD pattern; (b) cross-sectional TEM image of the $\mathrm{BiFO}_{3} /$ $\mathrm{Ni}$ tape; and (c) EDS mapping at different regions of the $\mathrm{BiFO}_{3} / \mathrm{Ni}$ tape. gesting the formation of pure $\mathrm{BiFeO}_{3}$ films directly on $\mathrm{Ni}$ substrate. The cross-sectional TEM image of the film is shown in Figure 1(b). A thin $\mathrm{NiO}$ layer between the $\mathrm{BiFeO}_{3}$ and the $\mathrm{Ni}$ is observed, which may be formed either before the deposition while the nickel is exposed to the atmosphere or oxygen diffusion through the $\mathrm{BiFeO}_{3}$ at the late stage of the film growth. For instance, an amorphous layer is often observed between the substrate and the film when PLD is used to deposit metal-oxide on $\mathrm{Si}^{20,21}$ It should be noted that the chemical information from different regions (see Fig. 1(b)) has also been mapped by EDS, where the sample was prepared by a focused ion beam technique. The EDS results confirm the chemistry from the top to the bottom being $\mathrm{BiFeO}_{3}, \mathrm{NiO}$, and $\mathrm{Ni}$ even though such a technique does not give an accurate determination of the composition.

The desired structural properties of $\mathrm{BiFeO}_{3}$ lead to high performance $\mathrm{BiFeO}_{3}$ directly on Ni. As shown in Fig. 2(a), polarization-electric field (P-E) loops measured at room temperature are as good as the $\mathrm{BiFeO}_{3}$ films on crystal ceramic substrates. ${ }^{19}$ The saturation polarization reaches $69 \mu \mathrm{C} / \mathrm{cm}^{2}$ under an electric field of $1300 \mathrm{kV} / \mathrm{cm}$. The remanent polarization of the $\mathrm{BiFeO}_{3}$ film is $53 \mu \mathrm{C} / \mathrm{cm}^{2}$. The shift of P-E loop to the right side can be attributed to the internal electric field, which has been also observed in $\mathrm{BiFeO}_{3}$ films by others. ${ }^{19}$ Figure 2(b) shows the piezoelectric response of the $\mathrm{BiFeO}_{3}$ film on the Ni tape. The piezoelectric $\mathrm{d}_{33}$ coefficient of $\mathrm{BiFeO}_{3}$ film is $52 \mathrm{pm} / \mathrm{V}$ at an electric field of $1000 \mathrm{kV} / \mathrm{cm}$. The asymmetric coercive fields observed in the piezoelectric curve further indicate the existence of built-in field in the $\mathrm{BiFeO}_{3}$ layer.
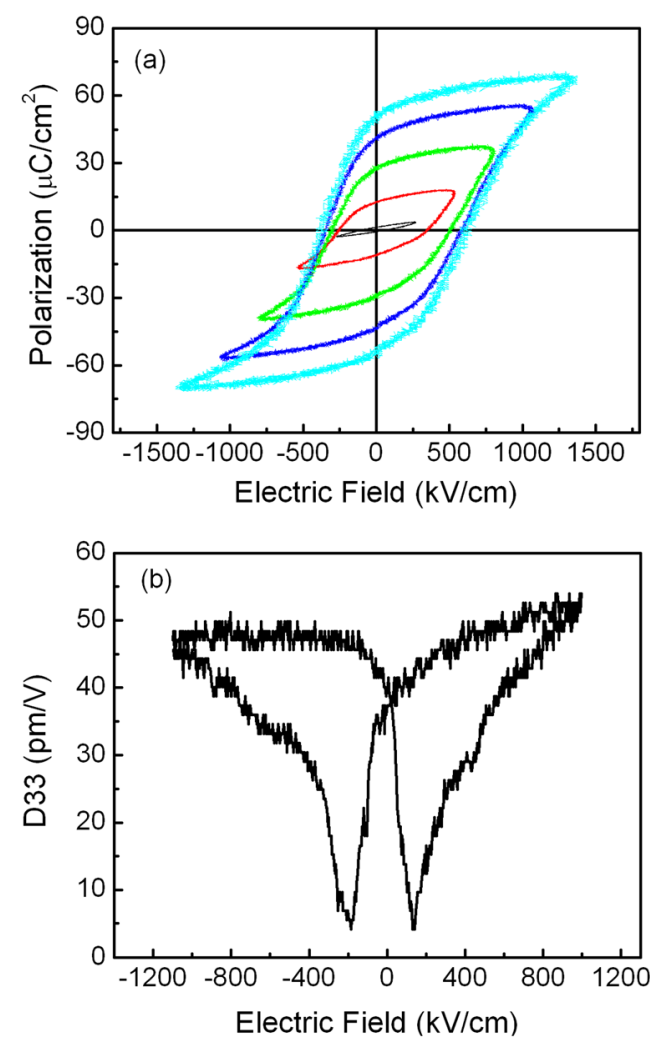

FIG. 2. Polarization and piezoelectricity of $\mathrm{BiFeO}_{3} / \mathrm{Ni}$. (a) Polarization as a function of electric field at room temperature and (b) piezo-response hysteresis loops for the $\mathrm{BiFO}_{3} / \mathrm{Ni}$ tape. 

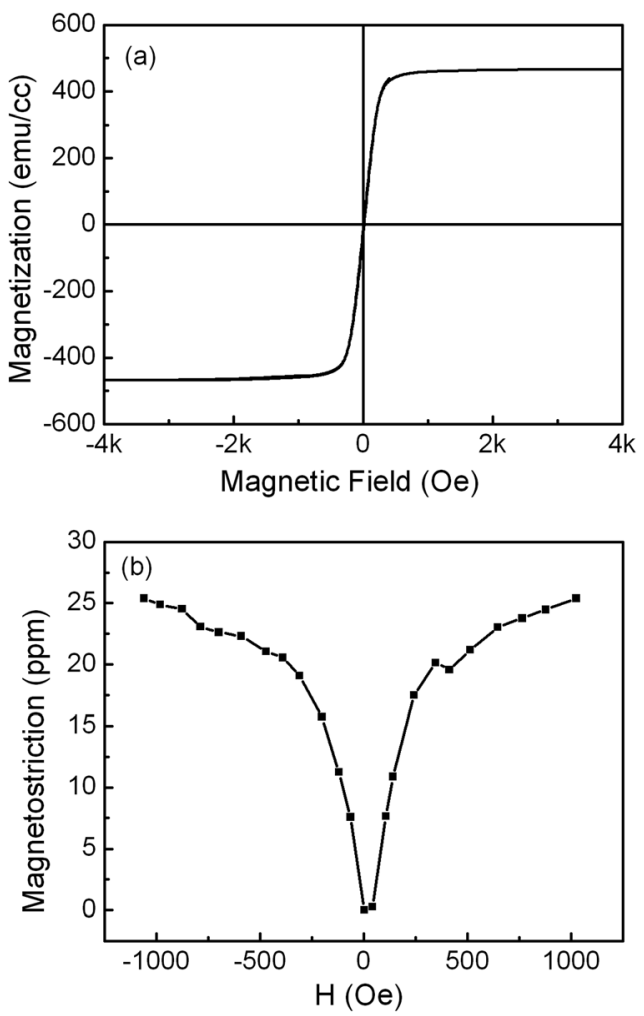

FIG. 3. Magnetization and magnetostriction of Ni substrate. (a) Magnetization as a function of magnetic field at room temperature and (b) magnetostriction as a function of magnetic field of the Ni substrate.

It is noted that the direct deposition of high performance ferroelectric $\mathrm{BiFeO}_{3}$ film on $\mathrm{Ni}$ tape does not degrade the magnetic properties of the Ni. This is important for applications if one wants to utilize the combined functionalities of both the film and the substrate. As given in Figures 3(a) and 3(b), the in-plane magnetization hysteresis and magnetostriction curve of nickel tape are measured by SQUID magnetometer and magnetic strain gauge at room temperature. The saturation magnetization is $467 \mathrm{emu} / \mathrm{cc}$. As a comparison, a normal bulk nickel has a magnetization of $490 \mathrm{emu} / \mathrm{cc}$. The maximum magnetostriction of nickel tape used in this experiment is $25 \mathrm{ppm}$ at $1 \mathrm{kOe}$ as shown in Fig. 3(b).

The most significant observation in our experiment is that $\mathrm{ME}$ effect is detected when $\mathrm{BiFeO}_{3}$ is directly deposited on $\mathrm{Ni}$ tape. In this experiment, we measured the $\mathrm{ME}$ response of $\mathrm{BiFeO}_{3} / \mathrm{Ni}$ by a traditional $\mathrm{AC}+\mathrm{DC}$ magnetic field method. While AC magnetic field was kept as $1 \mathrm{Oe}$ at $1 \mathrm{kHz}, \mathrm{DC}$ magnetic field slowly varied between $1 \mathrm{kOe}$ and $-1 \mathrm{kOe}$. In the measurement, both $\mathrm{AC}$ and $\mathrm{DC}$ magnetic fields were applied along the in-plane direction, and the electric polarization was measured along the out-of-plane direction. The maximum $\mathrm{ME}$ coefficient of $\mathrm{BiFeO}_{3} / \mathrm{Ni}$ is $3.5 \mathrm{mV} /$ $\mathrm{cm} \cdot \mathrm{Oe}$ when DC magnetic is around 100-200 Oe, as shown in Fig. 4. The ME output decreases with increasing DC magnetic field. It has been reported that $\mathrm{ME}$ output of $\mathrm{Ni} / \mathrm{PZT} / \mathrm{Ni}$ bulk ME sensor with 2-2 structure can have a value as high as $40-400 \mathrm{mV} / \mathrm{cm} \cdot O$. $^{22-24}$ The $\mathrm{ME}$ coefficient of our $\mathrm{BiFeO}_{3} / \mathrm{Ni}$ is much smaller than this value. It will be important to understand the limiting factors in order to maximize the ME output. It is well know that the ME coefficient of a composite can be expressed as

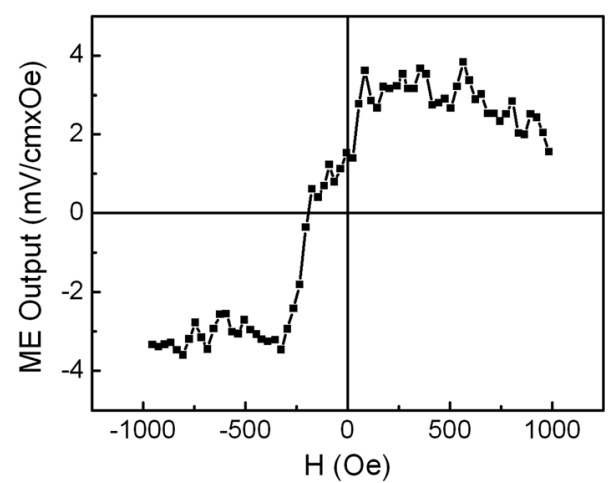

FIG. 4. Magnetoelectric coefficient of a $\mathrm{BiFeO}_{3} / \mathrm{Ni}$ tape as a function of the external magnetic field.

$$
\alpha=\frac{\partial P}{\partial H}=\frac{\partial P}{\partial S} \times \frac{\partial S}{\partial H},
$$

where $\mathrm{P}$ is the polarization, $\mathrm{S}$ is the strain, and $\mathrm{H}$ is the magnetic field. ${ }^{25,26} \partial P / \partial S$ and $\partial S / \partial H$ represent piezoelectricity and magnetostriction of the ferroelectric and ferromagnetic phases, respectively. Piezoelectric coefficient $\mathrm{d}_{33}$ of $\mathrm{BiFeO}_{3}$ film is around $69 \mathrm{pm} / \mathrm{V}$ due to the constraint of the substrate, while $\mathrm{d}_{33}$ of PZT ceramic could reach $750 \mathrm{pm} / \mathrm{V} \cdot{ }^{27} \mathrm{Ni}$ tape we are using in the experiment is nickel 201 alloy, which is stable at a temperature of $649^{\circ} \mathrm{C}$ and has a magnetostriction of $25 \mathrm{ppm}$. A value as large as $58 \mathrm{ppm}$ has been reported for a regular $\mathrm{Ni}$ single crystal by others. ${ }^{28}$ Accordingly, a relatively small $\mathrm{ME}$ coefficient of $\mathrm{BiFeO}_{3} / \mathrm{Ni}$ in this report is not unreasonable. One could potentially increase the ME output if the ferroelectric properties of $\mathrm{BiFeO}_{3}$ film are further optimized and Ni tapes with high magnetostriction are chosen.

In summary, we have directly deposited (110) preferred ferroelectric $\mathrm{BiFeO}_{3}$ films on flexible $\mathrm{Ni}$ tapes. Our results demonstrated that the $\mathrm{BiFeO}_{3}$ films have desired ferroelectric properties with a saturation polarization of $69 \mu \mathrm{C} / \mathrm{cm}^{2}$ and a piezoelectricity $\mathrm{d}_{33}$ of $52 \mathrm{pm} / \mathrm{V}$. The Ni tape, after the growth of $\mathrm{BiFeO}_{3}$, remains ferromagnetic with a saturation magnetization of $467 \mathrm{emu} / \mathrm{cc}$ and a maximum magnetostriction of $25 \mathrm{ppm}$. Additionally, The $\mathrm{ME}$ coefficient of the $\mathrm{BiFeO}_{3} / \mathrm{Ni}$ shows a maximum value of $\mathrm{V}_{\mathrm{ME}}=3.5 \mathrm{mV} / \mathrm{cm} \cdot$ Oe.

This work was performed, in part, at the Center for Integrated Nanotechnologies, a U.S. Department of Energy, Office of Basic Energy Sciences user facility at Los Alamos National Laboratory (Contract DE-AC52-06NA25396) and Sandia National Laboratories (Contract DE-AC0494AL85000). We also acknowledge the support of the U.S. Department of Energy through Los Alamos National Laboratory LDRD Program.

${ }^{1}$ G. Y. Yang, E. E. Dickey, and C. A. Randall, J. Appl. Phys. 94, 5990 (2003).

${ }^{2}$ A. I. Kingon and S. Srinivasan, Nature Mater. 4, 233 (2005).

${ }^{3}$ J. F. Tressler, S. Alkoy, and R. E. Newnham, J. Electroceram. 2, 257 (1998).

${ }^{4}$ T. Morita, M. K. Kurosawa, and T. Higuchi, Ultrasonics 38, 33 (2000).

${ }^{5}$ Z. Wang, L. Yan, Y. Yang, J. F. Li, J. Das, A. L. Geiler, A. Yang, Y. Chen, V. G. Harris, and D. Viehland, J. Appl. Phys. 109, 034102 (2011).

${ }^{6}$ G. M. Sessler, J. Acoust. Soc. Am. 70, 1596 (1981).

${ }^{7}$ S. R. Foltyn, N. Arendt, P. C. Dowden, R. F. DePaula, J. R. Groves, J. Y. Coulter, Q. X. Jia, M. P. Maley, and D. E. Peterson, IEEE Trans. Appl. Supercond. 9, 1519 (1999). 
${ }^{8}$ J. Shin, A. Goyal, S. Jesse, and D. H. Kim, Appl. Phys. Lett. 94, 252903 (2009).

${ }^{9}$ Z. Yuan, J. Liu, J. Weaver, C. L. Chen, J. C. Jiang, B. Lin, V. Giurgiutiu, A. Bhalla, and R. Y. Guo, Appl. Phys. Lett. 90, 202901 (2007).

${ }^{10}$ J. C. Jiang, E. I. Meletis, Z. Yuan, J. Liu, J. Weaver, C. L. Chen, B. Lin, B. Giurgiutiu, R. Y. Guo, A. S. Bhalla, D. Liu, and K. W. White, J. Nano Res. 1, 59 (2008).

${ }^{11}$ Y. Yang, Z. Wang, J. F. Li, and D. Viehland, J. Nanomater. 2010, 756319 (2010).

${ }^{12}$ T. Dechakupt, G. Yang, C. A. Randall, and S. Trolier-McKinstry, J. Am. Ceram. Soc. 91, 1845 (2008).

${ }^{13}$ I. Bretos, T. Schneller, R. Waser, D. F. Hennings, S. Halder, and F. Thomas, J. Am. Ceram. Soc. 93, 506 (2010).

${ }^{14}$ J. T. Dawley and P. G. Clem, Appl. Phys. Lett. 81, 3028 (2002).

${ }^{15}$ J. F. Ihlefeld, A. I. Kingon, W. Borland, and J. P. Maria, Mater. Res. Soc. Symp. Proc. 783, B3.2 (2004).

${ }^{16}$ J. P. Maria, K. Cheek, S. Streiffer, S. H. Kim, G. Dunn, and A. Kingon, J. Am. Ceram. Soc. 84, 2436 (2001).

${ }^{17}$ L. Bao, J. Ryley, Z. Li, C. Wilker, L. Zhang, D. Reardon, and R. Opila, J. Appl. Phys. 106, 114114 (2009).
${ }^{18}$ S. M. Aygun, P. Daniel, W. Borland, and J. P. Maria, J. Appl. Phys. 103, 084123 (2008).

${ }^{19}$ J. Wang, J. B. Neaton, H. Zheng, V. Nagarajan, S. B. Ogale, B. Liu, D. Viehland, V. Vaithyanathan, D. G. Schlom, U. V. Waghmare, N. A. Spaldin, K. M. Rabe, M. Wuttig, and R. Ramesh, Science 299, 1719 (2003).

${ }^{20}$ J. Q. He, S. Regnery, C. L. Jia, Y. L. Qin, F. Fitsilis, P. Ehrhart, R. Waser, K. Urban, and R. H. Wang, J. Appl. Phys. 92, 7201 (2002).

${ }^{21}$ H. F. Tian, H. X. Yang, H. R. Zhang, Y. Li, H. B. Lu, and J. Q. Li, Phys. Rev. B 73, 075325 (2006).

${ }^{22}$ S. N. Babu, A. Siddeshwar, K. Srinivas, S. V. Suryanarayana, and T. Bhimasankaram, J. Mater. Sci. 44, 3948 (2009).

${ }^{23}$ S. N. Babu, T. Bhimasankaram, and S. V. Suryanarayana, Bull. Mater. Sci. 28, 419 (2005).

${ }^{24}$ V. M. Laletin, N. Paddubnaya, G. Srinivasan, C. P. De Vreugd, M. I. Bichurin, V. M. Petrov, and D. A. Filippov, Appl. Phys. Lett. 87, 222507 (2005).

${ }^{25}$ R. M. Hornreich, IEEE Trans. Magn. 8, 584 (1972).

${ }^{26}$ C. W. Nan, M. I. Bichurin, S. X. Dong, D. Viehland, and G. Srinivasan, J. Appl. Phys. 103, 031101 (2008).

${ }^{27}$ S. E. Park and T. R. Shrout, Mater. Res. Innovations 1, 20 (1997).

${ }^{28}$ R. C. Hall, J. Appl. Phys. 30, 816 (1959). 